\title{
Previ: la tipología entre la fluidez de la vida y el rigor de la edificación*
}

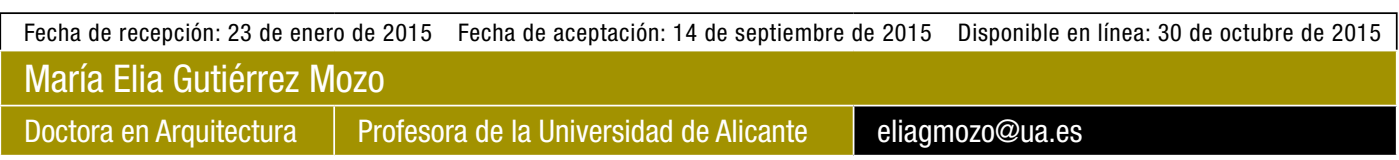

Raquel Pérez del Hoyo

\begin{tabular}{l|l|l}
\hline Doctora en Arquitectura & Profesora de la Universidad de Alicante & perezdelhoyo@ua.es
\end{tabular}

Resumen Hace diez años que el Proyecto Experimental de Vivienda (Previ), de Lima, a propósito de la convocatoria de investigación de la Bienal Iberoamericana de Arquitectura y Urbanismo celebrada en 2004 en esta ciudad, despertó un renovado interés en arquitectos jóvenes y comprometidos que se aproximaban a esta experiencia con la mirada atenta de quien desea aprender para construir vivienda social de irrenunciable vocación urbana. Asimismo, la asignatura pendiente de la industrialización en la vivienda de bajo coste ha propiciado el estudio de este caso. Después de plantear los aspectos básicos de Previ que nos permiten entenderlo y proyectarlo en su contexto, este artículo se acerca de nuevo a esa experiencia para leerla desde las claves proyectuales tipológicas que, a nuestro parecer, tienden un puente entre la vida que fluye (la utilitas) y el rigor que reclama la re edificatoria (la firmitas).

Palabras clave Lima; Previ; proyecto arquitectónico; proyecto de vida; proyecto urbano; vivienda social 


\section{Previ: the Typology between the Life Fluency and the Building Rigour}

Abstract Ten years ago the Experimental Project of Housing, Previ, in the city of Lima, after the call for research of the Ibero-American Biennial of Architecture and Urbanism, which was celebrated in relation to the call for investigation held in 2004 in this city by the Iberoamerican Biennale of Architecture and Planning, ten years ago the Experimental Housing Project (Previ), from Lima, awakened renewed interest among young and senior architects who were approaching this experience with the watchful eye of those who want to learn to build social housing with an inalienable urban vocation. Likewise, the unfinished business of industrialization in low-cost housing has led to the study of this case. After setting out the basics of Previ that allow us to understand and project it in context, this article analyzes that experience again in order to understand it from projectual typological keys that, from our point of view, build a bridge between life flowing (the utilitas) and the rigour that rebuilding demands (the firmitas).

Keywords Lima; Previ; architectural design; life project; urban project; social housing

\section{Previ: A tipologia entre a fluidez da vida e 0 rigor da construção}

Resumo Há dez anos que o Projecto Experimental de Habitação, Previ, de Lima, após a convocatória de investigação da Bienal Ibero-americana de Arquitectura e Urbanismo, celebrada em 2004 nesta cidade, tem demonstrado um interesse renovado por jovens arquitetos, que se comprometem e se envolvem nesta experiência com a visão atenta de quem deseja aprender, a fim de, por sua vez, construírem habitaçôes sociais de inegável vocação urbana. Entretanto, a actividade pendente da industrializaçáo na habitação de baixo custo desenvolveu o estudo deste caso. Este artigo, depois de considerar os aspectos básicos do Previ, que nos permitem entendê-lo e explicá-lo no seu contexto, aproxima-se novamente desta experiência, para lê-la a partir das chaves tipológicas de projecto, as quais, mais e melhor, tendem, segundo o nosso parecer, a surgir como uma ligação entre a vida que flui (utilitas) e o rigor que necessita a re aedificatoria (firmitas).

Palavras chave Lima; Previ; projeto de arquitectura; projeto de vida; projeto urbano; habitação social 


\section{Introducción}

"Dos hacen la ciudad: el negocio inmobiliario y los pobres". (Zabalbeascoa, 2011)

\section{El contexto}

Entre 1940 y 1961, la población de Lima pasó de 661.508 a 1.901.927 habitantes, como consecuencia de la migración a la capital desde las regiones andinas del Perú. Sin embargo, el crecimiento poblacional más importante se produjo en el período comprendido entre 1961 y 1972 (3.418.452 habitantes). La gente llegaba desde el campo a la ciudad en busca de una vida mejor, atraída por la concentración de actividades industriales y de servicios (Bonilla, 2009), en un éxodo rural que no era, en absoluto, ajeno al resto de América Latina, España y Portugal. Estas personas se instalaban en barriadas conocidas como "pueblos jóvenes" (Bonilla, 2009, p. 48) y las consecuencias de estas circunstancias indujeron la lógica preocupación estatal por la construcción de viviendas.

Durante el primer gobierno del arquitecto y urbanista Fernando Belaúnde (1963-1968) se construyeron 66.160 viviendas (Bonilla, 2009). Los programas de vivienda actuaron en tres direcciones: una, conjuntos habitacionales para la clase media; dos, desarrollo de urbanizaciones populares y tres, el Proyecto Experimental de Vivienda (Previ). Previ fue una iniciativa conjunta del Gobierno peruano, el Programa de las Naciones Unidas para el Desarrollo (PNUD), las Naciones Unidas (ONU) y el Banco de la Vivienda de Perú (Land, 2008). Se encomendó la dirección del proyecto al arquitecto británico Peter Land, quien, por encargo de la Yale University, había organizado un programa panamericano de posgrado sobre el planeamiento urbano y regional en la Universidad Nacional de Ingeniería (UNI) de Lima (Land, 2008). Los acuerdos se firmaron en septiembre de 1968. El Gobierno peruano aportaba el solar (la parcela), los fondos para la construcción y el personal local, mientras la ONU y el PNUD proporcionaban el apoyo técnico, el personal internacional y los costes del concurso internacional (Land, 2008), el cual se convocó en 1969.

El Previ contemplaba tres proyectos piloto: el PP1 —objeto de este artículo—, que trataba del diseño y de la construcción de un barrio nuevo; el PP2, que consistía en un estudio de regeneración de una barriada muy deteriorada y el PP3, en la planificación de solares y servicios para racionalizar la autoconstrucción de viviendas, es decir, hacerla más ordenada, eficiente y segura. El objetivo último era desarrollar métodos y técnicas que pudieran ser aplicados a gran escala, como parte de la política peruana de la vivienda. Los proyectos piloto fueron finalmente cuatro: el PP3 fue un proyecto de autoconstrucción del Ministerio de Vivienda y el PP4 un proyecto de reconstrucción tras el terremoto de 1970, basado en sistemas sismorresistentes, con recursos materiales locales y métodos de autoconstrucción (Land, 2008).

\section{El Proyecto Piloto PP1}

Las bases del concurso internacional que se convocó para llevar a cabo el primer proyecto piloto de Previ abogaban por la Vivienda de Baja 
Altura y Alta Densidad (BAAD) como alternativa para América Latina (Samper, s. f.; Previ-Lima. Low Cost Housing Project, 1970), en donde la vivienda urbana mayoritaria es individual porque, para los ricos, es un signo de distinción $y$, para los pobres, es una tabla de salvación, ya que constituye la posibilidad de hacerla crecer conforme a necesidades y recursos (vivienda progresiva). La vivienda unifamiliar produce ciudad dispersa, de baja densidad, escasos servicios y alto costo. La otra posibilidad de organización de la vivienda en la urbe - los bloques - no está al alcance de los más pobres, por la repercusión de los costes de los servicios comunes del inmueble en el precio de la vivienda y los ricos no quieren vivir en ellos.

Por tanto, la solución apuntaba a atender tres requerimientos: uno, el aumento de la densidad; dos, la búsqueda de un tipo de vivienda urbana capaz de hacer ciudad y tres, la asunción de los asentamientos informales, para mejorar sus condiciones, entendidos como transición hacia nuevos modos de habitación. Entre la vivienda de baja altura y baja densidad característica de la ciudad jardín (elitista y antiurbana) y la vivienda en altura de alta densidad propia de la ciudad moderna (apta para la clase media, pero inaccesible para los más desfavorecidos), la tercera vía es la vivienda de baja altura y alta densidad.

Estos fueron los objetivos del planteamiento del Previ:

1. Pensar una célula de vivienda susceptible de crecer, que integra desde el proyecto la capacidad constructora de sus habitantes, un recurso de provecho cuando los de la administración son escasos.

2. Proyectar formas de asociación y crecimiento para crear auténticos vecindarios.

3. Apostar por conglomerados muy compactos, estructurados por calles estrechas y peatonales y con muchas plazas vecinales pequeñas.

4. Plantear un sistema de prefabricación de bajo coste y montaje en seco que, de paso, impulsara la industria local (Montaner, 2008, p. 108).

En consecuencia, las bases del concurso (Samper, s. f.) solicitaban un proyecto de viviendas de bajo costo y crecederas para 1.500 familias, en solares de 80 a $150 \mathrm{~m}^{2}$ y con casas de 60 a $120 \mathrm{~m}^{2}$, de una o dos plantas, capaces de soportar una tercera y un diseño del conjunto. El terreno, de 40 ha, a $8 \mathrm{~km}$ al norte del centro de Lima y conectado a una red local de vías y al sistema metropolitano de carreteras, formaba parte de una extensión de 400 ha que serviría de reserva para futuras ampliaciones. De otro lado, habría que tomar en consideración las condiciones geográficas y meteorológicas propias de la ciudad de Lima, que tiene una altura de 137 metros sobre el nivel del mar, poca lluvia, pero alta humedad; los días son cálidos, pero las noches frescas; el viento es suave y la luminosidad abundante. Además, se recomendaba prestar atención a los equipamientos públicos; a la limitación y segregación de la circulación rodada; al espacio libre y a la estandarización. Se invitó a trece equipos internacionales (de arquitectos "estrellas", la mayoría de ellos ${ }^{1}$ con 40 años de edad, lo cual supuso una innovación en

\footnotetext{
Atelier 5 había hecho la brutalista Siedlung Halen. Kikutake (1928-2011), Maki (1928) y Kurokawa (1934-2007) eran famosos por el Movimiento Metabolista. Herbert Ohl (1926-2012) trabajaba en la construcción y el diseño industriales. Christopher Alexander (1936) ya había publicado Community and Privacy, Notes on the Synthesis of Form y A city is not a tree. Candilis (1913-1995), Josic (1921-2011) y Woods (1923-1973) habían trabajado con Le Corbusier en la Unidad de Habitación de Marsella. Charles Correa (1930) trabajaba en la apropiación de la Modernidad desde el tercer mundo. Oskar Hansen (1922-2005) y Svein Hatloy (1940) habían hecho vivienda estatal en PoIonia y trabajado en la participación de los usuarios en los procesos creativos. José Luis Íñiguez de Onzoño (1927) y Antonio Vázquez de Castro (1929) habían hecho Caño Roto en Madrid. Toivo Korhonen (1926-2014) era discípulo de Alvar Aalto. James Stirling (1926-1992), famoso mundialmente, estaba trabajando en su Complejo Residencial Runcorn New Town. Knud Svenssons (1925) había trabajado la prefabricación en el barrio Albertslund. Aldo van Eyck (1918-1999) fue fundador del Team 10. Samper (1924) había hecho, con sus socios Esguerra, Saénz y Urdaneta, La Fragua en Bogotá.
} 
el planteamiento, a la vez que se esperaba originalidad en las respuestas) y otros tantos peruanos, por medio de un concurso. Este artículo se centra en los primeros, por cuanto son arquitectos de reconocido prestigio, lo que permite contextualizar sus propuestas en el conjunto de su obra y su trayectoria.
Se otorgaron seis premios (tres internacionales y tres peruanos) y se contrató a todos los equipos para hacer unas veinte casas cada uno en un solar reducido. El diseño definitivo de este conjunto-mosaico fue responsabilidad del equipo peruano. Las propuestas (trece) y los premios (tres, marcados en negrilla) fueron (Figura 1):

Figura 1.

Plano del conjunto

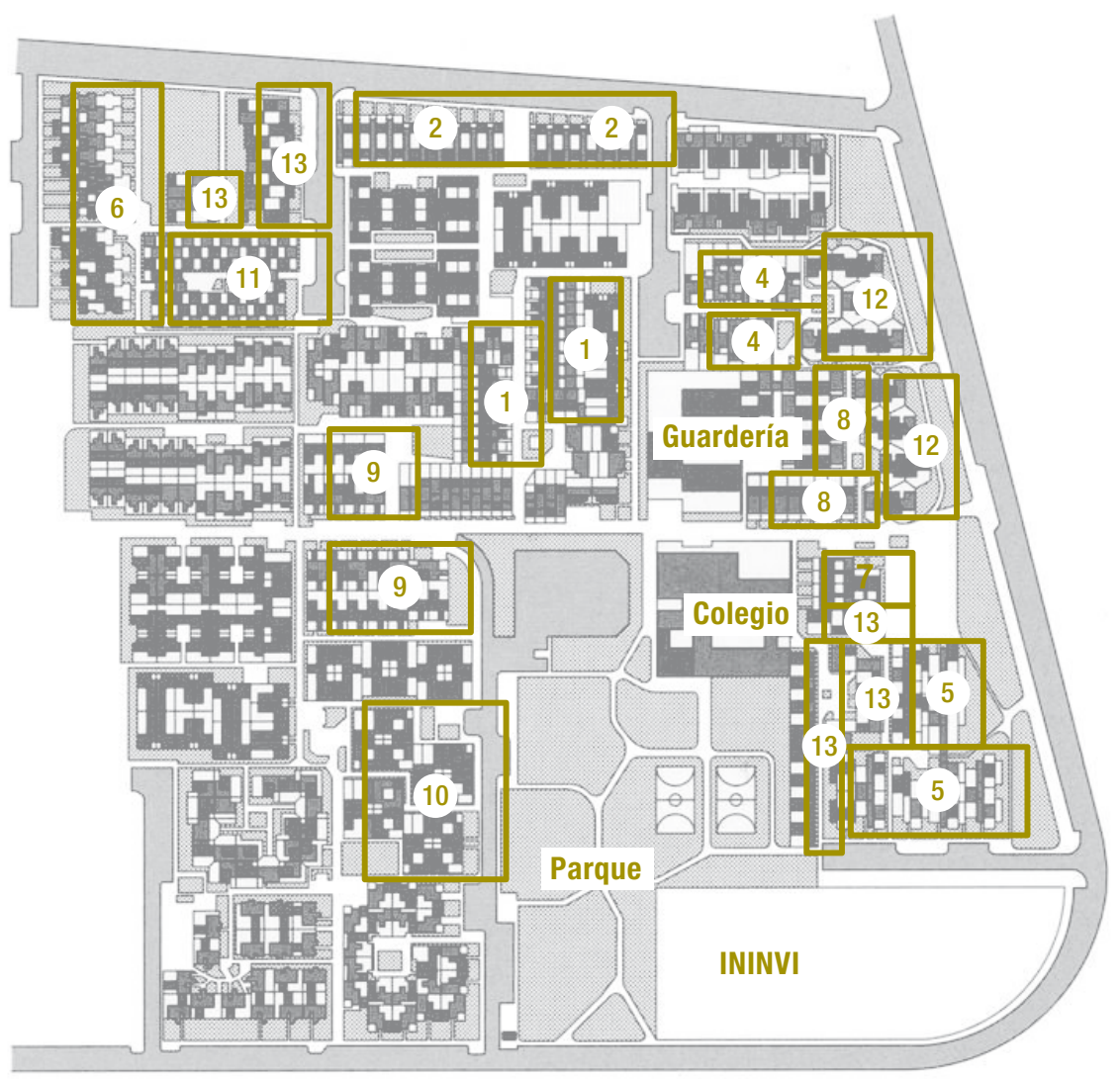

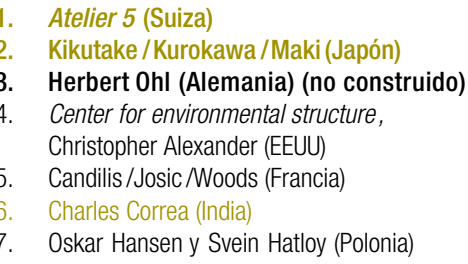

8. I Íniguez de Onzoño y Vázquez de Castro (España)

9. Toivo Korhonen (Finlandia)

10. James Stirling (Reino Unido)

11. Knud Svenssons (Dinamarca)

12. Aldo E. van Eyck (Holanda)

13. Esguerra/Sáenz/Urdaneta/Samper (Colombia)
NOTA:

En negrilla, los proyectos premiados. En amarillo, los proyectos analizados. 


\section{Objetivos}

Previ ha sido estudiado desde diversos puntos de vista, entre los cuales se destacan dos: el primero de ellos se interesa por el impacto del tiempo sobre esta experiencia y registra, casi con vocación de levantar un acta notarial, cómo, de hecho, las viviendas han crecido, se han transformado y vinculado estos procesos a las propias biografías de las familias que las ocupan y comparecen con nombres y apellidos en el estudio (García-Huidobro, Torres Torriti, Tugas, 2005; 2008; 2010). La intención de esta perspectiva bien podría resumirse en la aportación de Pérez Pérez y González Couret (2011), es decir, en evaluar la experiencia y tomar nota de sus aciertos y de sus errores con vistas al proyecto de arquitectura, como fermento del mismo. La otra línea de interés que Previ ha despertado tiene que ver con la tecnología, esto es, con la auditoría de la experiencia desde un punto de vista de la construcción y su relación con la industria (Lucas, Salas y Barrionuevo, 2012), asignatura pendiente de la modernidad, antes y ahora.

Pues bien: si aceptamos la vigencia de la terminología vitruviana y sus razones de la arquitectura y si podemos convenir en que los acercamientos al Previ se han producido sobre todo desde la esfera de la utilitas (cómo ha funcionado o ha dejado de funcionar el proyecto años después de su implementación) y de la firmitas (qué ha supuesto o ha dejado de suponer la prefabricación e industrialización en la experiencia), esta aportación se propone el estudio del Previ desde la venustas, por cuanto pretende un análisis tipológico que indague en la colaboración activa que las formas, en cuanto estructuras formales (Martí, 2014) y sus articulaciones, han prestado a la consecución de los objetivos del concurso y, por ende, qué enseñanzas disciplinares podemos extraer del mismo, más allá del tiempo y del lugar de la experiencia objeto de estudio. Dado este enfoque desde el tipo arquitectónico, se ha trabajado sobre las plantas de los proyectos, redibujadas y tratadas gráficamente en los casos examinados y con las originales en el resto.

La documentación gráfica elaborada contiene y revela los aspectos o atributos que el nuevo análisis contempla; constituye parte esencial del mismo, por cuanto se enfoca, en primer lugar, en señalar los dispositivos de crecimiento de los proyectos, tanto dinámicos (patios, jardines y terrazas que posibilitan una extensión horizontal de la vivienda) como estáticos (escaleras e instalaciones cuya prolongación en altura permite el crecimiento vertical). En segundo lugar, se muestra la disposición de los espacios de uso privativo y de uso común y sus relaciones articuladas por las circulaciones para integrar ambas estructuras formales en un programa que, a la vez, es funcional (vital) y técnico (constructivo) y configura una estructura formal, es decir, un tipo arquitectónico.

\section{Metodología}

Para la consecución de nuestros objetivos, hemos seleccionado cuatro proyectos de los trece internacionales, con base en una serie de criterios que justifican la elección.

\section{Proyectos seleccionados}

Las cuatro propuestas - los dos primeros coincidentes con los premios concedidos ${ }^{2}$ - que hemos seleccionado para análisis son: 
, Atelier 5 (Suiza)

' Kikutake/Kurokawa/Maki (Japón)

, Charles Correa (India)

' Knud Svenssons (Dinamarca)

Se siguieron los siguientes criterios:

1. Que el proyecto se hubiera ejecutado, para evaluar las adiciones y los cambios "de hecho" introducidos por los habitantes sobre la idea original, información recabada en el trabajo de García-Huidobro, Torres Torriti y Tugas (2008), base del nuestro en este aspecto.

2. Que el proyecto se hubiera demostrado capaz de crecimiento.

3. Que el atractivo del producto final no fuera deudor de las incertidumbres que plantea un proceso de crecimiento abierto. Esto nos llevó a no contar con propuestas de arquitectos de prestigio, como Aldo van Eyck o James Stirling.

4. Que la solución, además de haber propiciado un desarrollo útil, fuera representativa de otras similares, sin reiteraciones. La propuesta escandinava de Toivo Korhonen puede asimilarse a la danesa de Knud Svenssons, que preferimos por su claridad.

5. Que la cultura subyacente a la propuesta fuera afín a la propia del lugar, lo que incumplen algunos proyectos, de inequívoca matriz europea.

6. Que la incidencia discreta de una prefabricación ligera y asequible hubiera producido el ahorro económico, imperativo en este caso.

7. Que la interacción de lo privado y lo público fuera intensa, eficaz y diluyera sus fronteras, lo cual nos conduce a modelos que la civilización europea canceló hace siglos y perviven en otras áreas del planeta, como la hindú.

\section{Comentarios a la idea del concurso}

En la idea del concurso se dan cita dos proyectos que se cruzan: un proyecto de vida (el del habitante) y un proyecto de arquitectura (el de la habitación). Se trata de con-jugar ambos, sin con-fundirlos, porque ni la arquitectura (un arte útil) es vital ni la vida es arquitectónica (arte de construir). Entre la arquitectura (edificación) y la vida (función) se crea una tensión que es importante distender, sin detrimento de una u otra, a lo cual acude el arte (forma) y apela a la sensibilidad. El arte participa de la vida (concreta) y de la ciencia (abstracta), por cuanto, sin renunciar a lo inmediato, aspira a una validez universal de sus formas, concretas y abstractas al mismo tiempo. El modo de pensar que atiende a la vida es subjetivo; la ciencia aspira a hacer del pensamiento un uso objetivo y el arte se mueve entre lo subjetivo de las personas (autor —arquitecto- - y público - usuarios-) y lo objetivo de las obras (de arquitectura). Por tanto, la razón apenas se emplea en el discurso cotidiano y tópico, se ejerce con todo rigor en el discurso científico y cede, en parte, a afectos irracionales, sentimientos y emociones en el discurso del arte.

El arte es, pues, racional e irracional, por eso se postula como intermediario entre la cotidianidad instintiva e irracional y la ciencia intelectiva y racional y, por eso, a la arquitectura — con estructura racional (o no), pero que está al servicio de la vida, en parte irracional- le corresponde el estatuto de arte. En términos lukacsianos, se puede decir que la arquitectura incide en los tres lenguajes: en el cotidiano (inmediato y particular), por razón de su utilidad; en el científico (mediado y general), que está en la base de sus cálculos y equipos y en el estético (inmediato y general), a cuya sensibilidad apela. 
Se trata, entonces, de entender la casa como proceso, abierto e indeterminado y no como objeto, acabado, definido, cerrado. La vivienda como actividad capaz de atender a tres solicitaciones que se suceden: una, satisfacer una necesidad actual; dos, capitalizar a los pobres (la casa, artefacto de renta) y tres, que estos tengan acceso a mayores y mejores oportunidades. El objetivo es, en definitiva, transformar el gasto social en inversión social y, para ello, hay dos estrategias: la tipología establecida (de baja altura y alta densidad) y la autoconstrucción (la cual entraña un riesgo, pues, al no ser algo natural, tiene que valerse de operarios que conozcan sus respectivos oficios). El recurso a los obreros de construcción es imprescindible y su coordinación necesaria; prescindible es, en cambio, el arquitecto que coordina.

No obstante, en el proyecto de arquitectura es competente el arquitecto, como en el proyecto de vida es competente el habitante. Ni del habitante se puede esperar una edificación racional (la única económica y sostenible) ni el arquitecto tiene por qué gobernar la vida del habitante. Otra cosa es que el arquitecto trace las líneas maestras del edificio (estructura, espacios y servicios, lo que, desde la actual experiencia chilena de Elemental, Alejandro Aravena llama "las partes difíciles" de la construcción) y que luego el habitante los acomode a su circunstancia con ayuda de oficiales competentes.

En el proceso discernimos dos fases: primera, arquitecto y operarios; segunda, operarios y habitante. No son dos procesos, sino uno mismo, de cuya continuidad depende la fortuna de la operación. Si esta se rompe, entramos en la ruina y consiguiente restauración que tratamos de evitar. En cuanto a la prefabricación, el montaje (fácil en el mueble —el Do it yourself-, pero imposible en el inmueble) concierne a profesionales. De hecho, todas las críticas sobre el Previ coinciden en el mismo punto: Jacques Crousse (2008) piensa que el concurso acabó por dar lugar a un muestrario, por lo que ningún sistema constructivo pudo ser desarrollado e industrializado.

Por lo demás, tampoco hubo una asistencia a los habitantes para acometer la ampliación de sus casas, circunstancia en la que insiste Peter Land (2008) cuando valora la experiencia del Previ treinta años después: no se gestionó el mantenimiento del barrio ni se orientaron los crecimientos de las casas. De la comparación de los resultados del Previ con los de otros asentamientos informales en ciudades latinoamericanas, salta a la vista el protagonismo del proyecto de arquitectura en su consecución.

La lección que de él se desprende está en la base misma del renovado interés por los ensayos de vivienda masiva que, en Chile, lidera el mencionado Alejandro Aravena, promotor de vivienda autoconstruible y evolutiva mediante el Concurso Elemental Chile (2003) que, organizado por las escuelas de Arquitectura de la Pontificia Universidad Católica en Santiago y de la Harvard University en Boston, ha propiciado siete conjuntos a lo largo del territorio, realizados por equipos formados por los ganadores, arquitectos y estudiantes (Fique Pinto, 2006).

\section{Comentario breve a las propuestas no analizadas}

\section{Herbert Ohl (Alemania)}

Asociar módulos humanos de habitación con módulos técnicos de construcción ha sido, desde la época del Werkbund alemán, objetivo principal del arquitecto. El proyecto juega con la disonancia (discreta) entre el anillo prefabricado (la unidad 
de construcción) y el lote ocupado (la unidad de habitación), lo que permite el desplazamiento de los anillos y la creación de patios. Por su tecnología innovadora al servicio de una vivienda flexible, la propuesta fue premiada ${ }^{3}$, pero no se la llevó a cabo, por lo que descartamos su análisis (Figura 2).

Figura 2.

Proyecto de Herbert Ohl (Alemania)
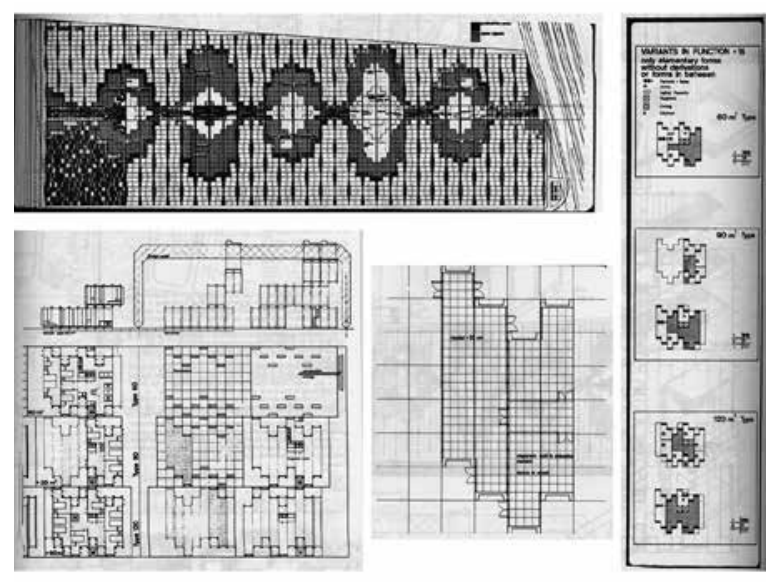

Fuente: Samper (s. f., p. 5)

\section{Center for environmental structure, Christopher Alexander (Estados Unidos)}

El estudio, minucioso en el detalle y un tanto naïf, convierte el espacio peatonal en auténticas islas, al deprimir las calles de tráfico envolventes. La combinación de materiales (plástico y bambú) sugiere un afán cosmopolita, como de aldea global avant-la-lettre, en la línea de los patterns del mismo autor. El jurado valoró la variedad de soluciones para que cada familia pudiera elegir " a la carta", pero el modelo pareció un tanto obsoleto y las calles no estaban bien resueltas. Parte del jurado, sin embargo, destacó el bajo costo de su opción (Figura 3).
Figura 3.

Proyecto de Center for environmental structure, Christopher Alexander (Estados Unidos)
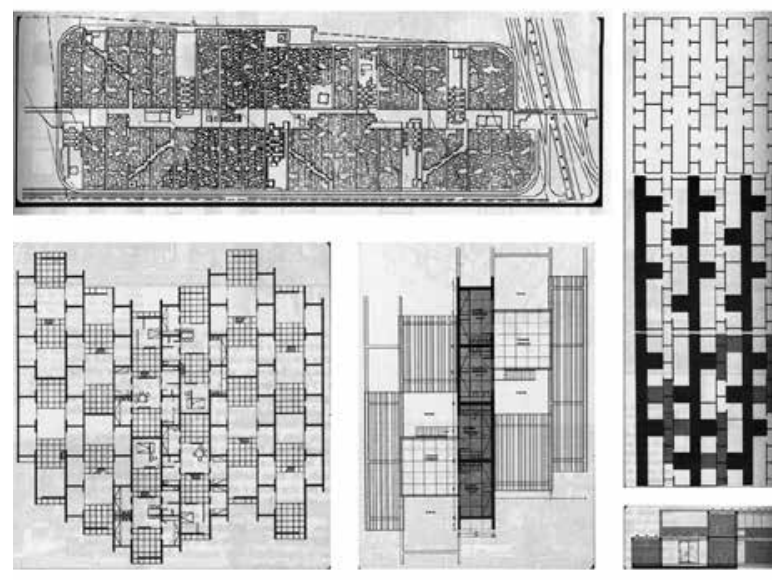

Fuente: Samper (s. f., p. 6)

\section{Candilis, Josic y Woods (Francia)}

En la propuesta priman la construcción (con cubiertas de asbesto cemento) y la medida (una modulación de base 0,90 metros que asigna a cada casa un elemento de 4,50 en una planta y dos de 2,70 en dos alturas). Se impone una racionalidad a rajatabla, a la vez que se respira un aire provisional de cara a un futuro incierto (Figura 4).

Figura 4

Proyecto de Candilis, Josic y Woods (Francia)
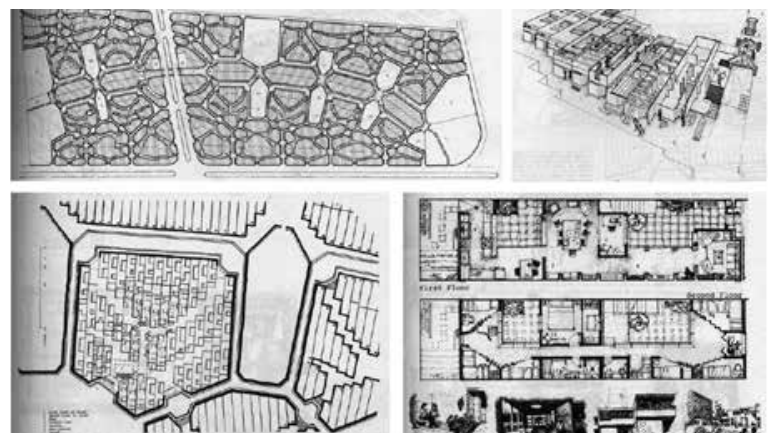

Fuente: Samper, G. (s. f., p. 7) 


\section{Oskar Hansen y Svein Hatloy (Polonia)}

Respuesta demasiado literal y, tal vez, poco imaginativa a las bases del concurso. Se cuida la vecindad a la red viaria y la no interferencia entre los ritmos de construcción. Se plantean dos momentos en la construcción: uno inicial para la estructura (prefabricada) y otro posterior para lo demás, llevado a cabo por el habitante (Figura 5).

Figura 5.

Proyecto de Oskar Hansen y Svein Hatloy (Polonia)
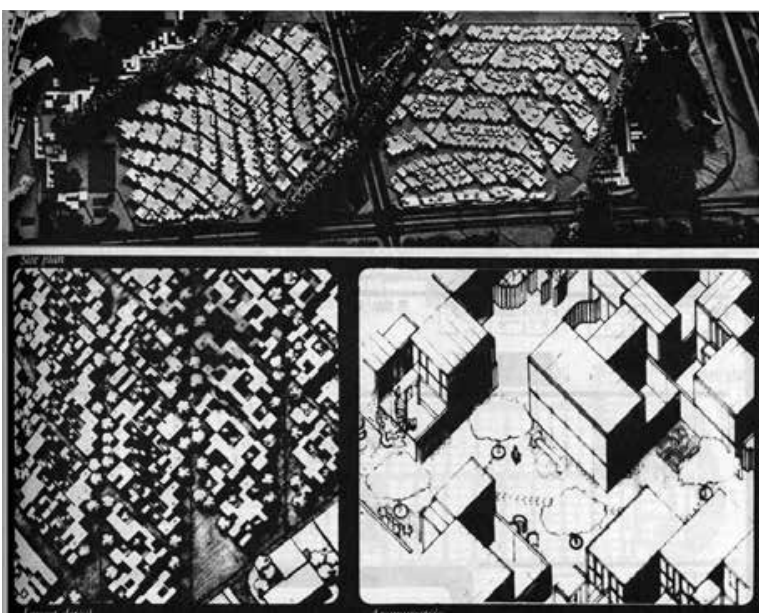

Fuente: Samper (s. f., p. 9)

\section{Iñiguez de Onzoño y Vázquez de Castro (España)}

Posee la belleza del hallazgo al margen de su pertinencia. Una solución lógica que la práctica quizás desmerecería. En esta propuesta hay una dosis de utopía que salta a la vista (Figura 6).

Figura 6.

Proyecto de Î̃íiguez de Onzoño y Vázquez de Castro (España).
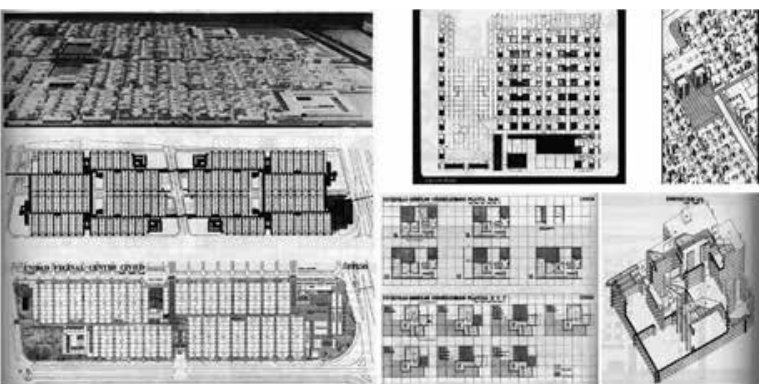

Fuente: Samper (s. f., p. 10)

\section{Toivo Korhonen (Finlandia)}

Propuesta inteligente, pero poco práctica, debido a su alto grado de abstracción, que deja demasiadas cosas (las zonas verdes, por ejemplo) a merced de unos habitantes a los que se supone responsables y comprometidos (Figura 7).

Figura 7

Proyecto de Toivo Korhonen (Finlandia)

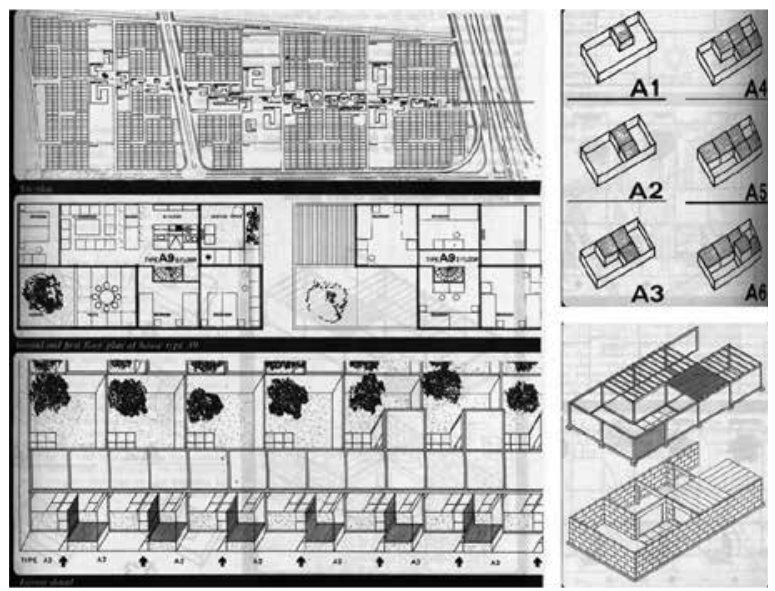

Fuente: Samper (s. f., p. 11)

\section{James Stirling (Reino Unido)}

El arquitecto deja constancia de su talento, tanto en la amable vecindad de la trama urbana como en la calidad indiscutible de sus casas que crecen, como siempre lo han hecho, a imitación de los seres vivos: hacia arriba. La objeción que puede hacerse a esta elegante propuesta es su perfección, lo que la inhabilita para ser manipulada. De hecho, el proyecto prevé un crecimiento primero alrededor del patio y otro después, en planta alta, que mantiene los vacíos. La realidad ha pasado por ocupar el patio y, en consecuencia, dar al traste con la hermosa idea generadora de la vivienda. Las casas se agrupan en cuatro vecindarios, entre los que se proyectan parques y dotaciones para la comunidad (Figura 8). 
Figura 8.

Proyecto de James Stirling (Reino Unido)
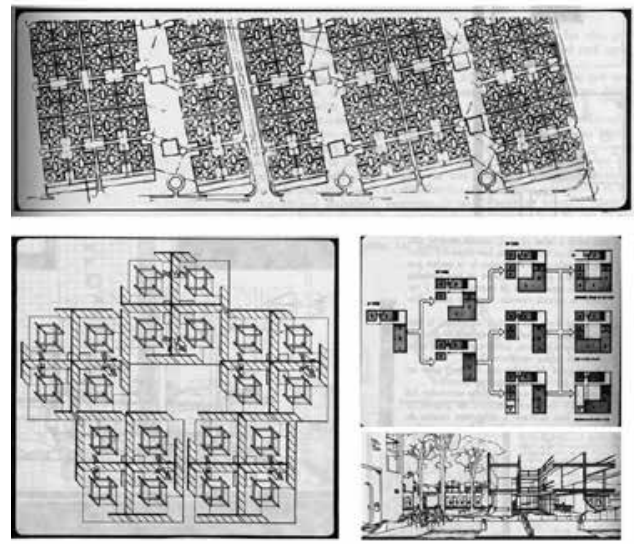

Fuente: Samper (s. f., p. 12)

\section{Aldo E. van Eyck (Holanda)}

Solución sutil y dúctil, que parte de una geometría rigurosa y compleja entre calles paralelas, a la vez que contempla, en sus senderos sinuosos, las irregularidades del territorio. Se hace especial hincapié en el curso de los vientos, fuera y dentro de las viviendas y se otorga las debidas reserva y seguridad a la vida vecinal y lúdica: juegos de nińos, prados comunales, plazas con fuentes. No queda claro el discurso de crecimiento. La propuesta apunta al fin. Sabemos a dónde vamos a parar, pero se nos oculta de dónde partimos. La cocina conforma el corazón de la vivienda, dispuesta alrededor de ella y hasta colmatar los límites paralelos de la parcela, tanto en la planta baja como en la alta (Figura 9).

\section{Esguerra, Sáenz, Urdaneta y Samper (Colombia)}

Combina el detalle autóctono a pequeña escala con una organización moderna, importada, del espacio urbano. El planeamiento atiende más al crecimiento del barrio que al de sus módulos domésticos. De ahí que la propuesta acuse rasgos propios de una urbanización convencional (Figura 10).
Figura 9.

Proyecto de Aldo E. van Eyck (Holanda)
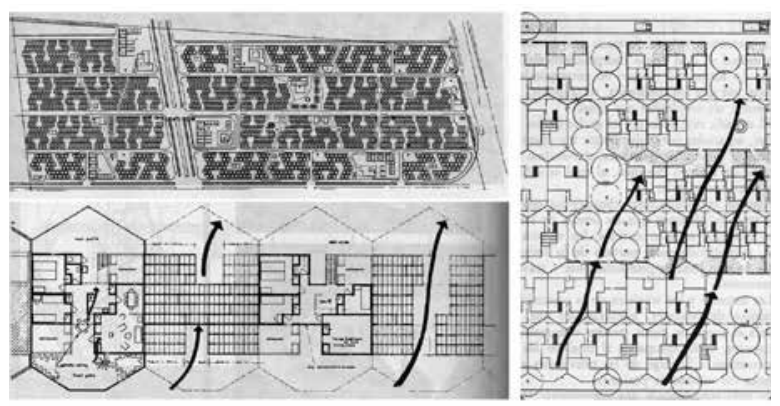

Fuente: Samper (s. f., p. 14)

Figura 10.

Proyecto de Esguerra, Sáenz, Urdaneta y Samper (Colombia)

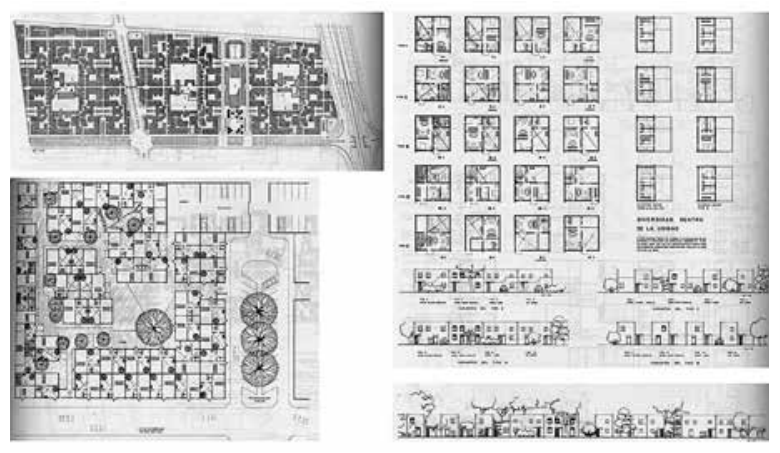

Fuente: Fuente: Samper (s. f., p. 15)

\section{Resultados: comentarios a las propuestas objeto de este análisis}

\section{Atelier 5 (Suiza)}

El jurado valoró su sistema constructivo, que emplea los mismos elementos en paredes y techos para reducir costes y la riqueza espacial de la casa, así como su agrupación en torno a pequeńas plazas con equipamientos de vecindad. En la intención de los promotores del Concurso, había sido factor determinante el 
crecimiento: "creced y multiplicaos" es una consigna que la ciudad toma de los seres vivos. Se trata, pues, de confiar, en lo posible, si no en la multiplicación, al menos en el crecimiento, la voluntad o el arbitrio de los habitantes. El propósito que contempla esta solución es que la casa pueda crecer con facilidad, en proporción de 9 a 4 y en aquellas partes que con independencia lo requieran. Mediante una prefabricación in situ y sin maquinaria pesada, se ofrece a los habitantes terminar, modificar y mejorar sus habitaciones.

Se presta especial atención a la orientación de todas las unidades (lo que impone rigor en los ejes) y a su mejor ventilación, al margen de su ubicación. De hecho, hay una asombrosa variedad y riqueza en la composición. No hay cisma entre lo público y lo privado: solo matices y se practica la necesaria segregación del tráfico, lo que, además de razones de seguridad, garantiza una decisiva reducción del ruido ambiental. El conjunto se nos ofrece como un campo imantado, en donde cada módulo cae donde cae, libre, pero se posiciona (orienta) sin titubear del mejor modo posible, al tener en cuenta que, en este aspecto, lo mejor es mejor para todos (Figura 11).
La idea feliz de esta propuesta quizás estriba en la ubicación de los espacios de la familia en el piso intermedio, lo que permite a la vivienda crecer en dormitorios y servicios, hacia arriba y hacia abajo. En este proyecto, el crecimiento en ambos sentidos ha sido determinante. Se asume que en la familia suceden cambios insospechados y se atiende con esmero a sus ritos y ceremoniales propios que, de ningún modo, son ajenos a la modestia de este género de habitaciones. Es más: porque los medios son limitados, el valor concedido a los protocolos es muy apreciado. Así, del acto de las comidas, el proyecto hace tres lecturas matizadas: la informal de sus miembros, la familiar que celebra su reunión y la que ejerce como anfitriona de invitados ajenos y concomitantes.

En cuanto a los patios, vemos que existen tres: dos de ellos en la transición con el espacio público, para que la vivienda crezca y, además, diversifique usos (comercial, por ejemplo) con acceso independiente a los mismos desde la calle. En la variante tipológica que cierra la hilera, los patios se reducen a dos, pero se mantiene la idea de la sección y la alternancia, en la planta elevada, entre terrazas y espacios cerrados (Figuras 12 y 13$)$.

Figura 11

Proyecto de Atelier 5 (Suiza)
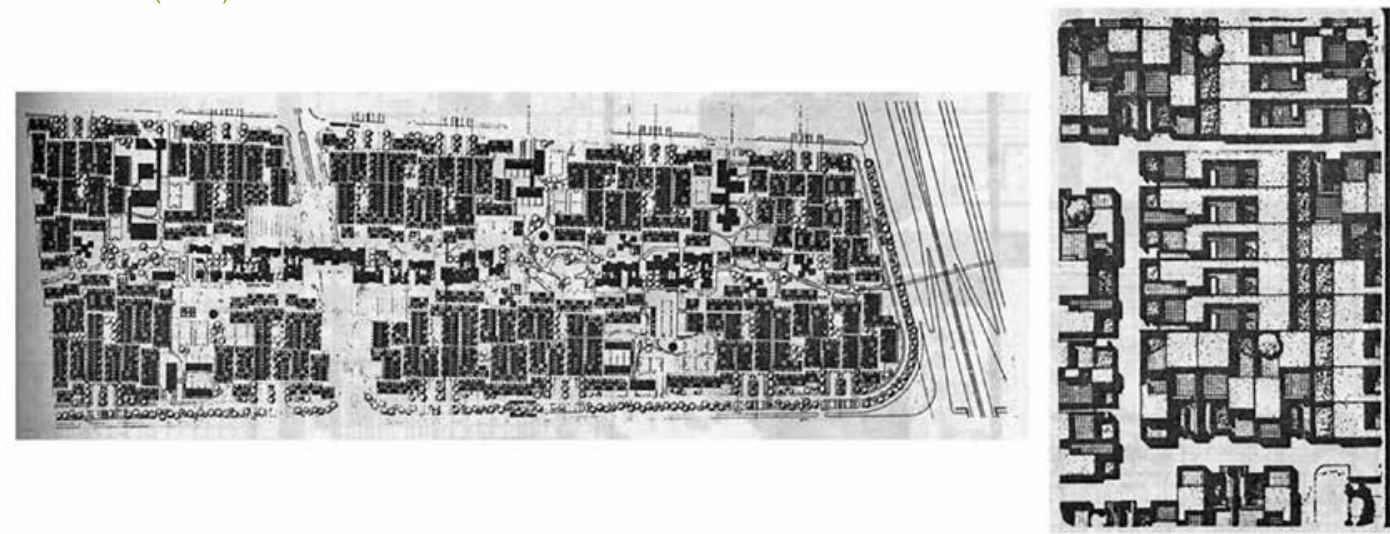

Fuente: Samper (s. f., p. 3) 
Figura 12.

Proyecto de Atelier 5 (Suiza), casa en hilera. Dispositivos de crecimiento, funcionamiento e integración
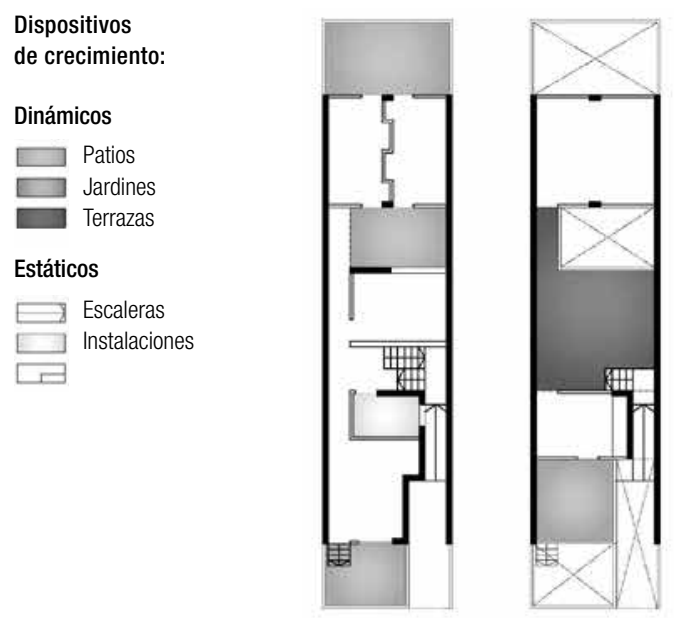

Funcionamiento

Uso privado

$\square$ Uso común

Circulaciones
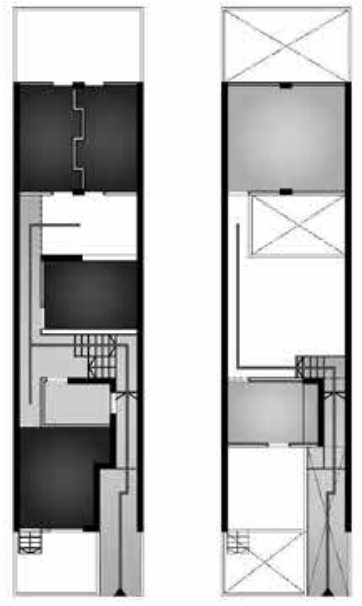

Integración:

Programa funcional

D: Dormitorio

S: Sala de estar

C: Comedor

K: Cocina

L: Lavadero

B: Baño

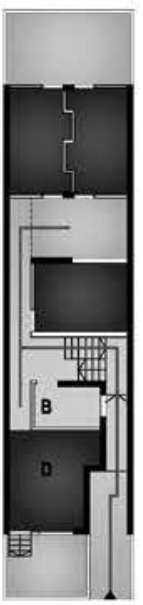

Figura 13.

Proyecto de Atelier 5 (Suiza), casa final de hilera. Dispositivos de crecimiento, funcionamiento e integración

Dispositivos de crecimiento:

Dinámicos

$\square$ Patios

$\square$ Jardines

Terrazas

Estáticos

$\square$ Escaleras
$\square$ Instalaciones
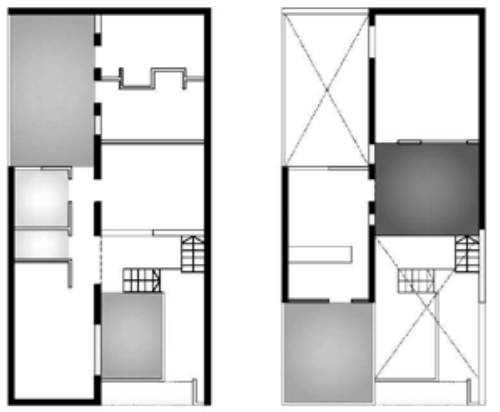

Funcionamiento

Uso privado

$\square$ Uso común

Circulaciones
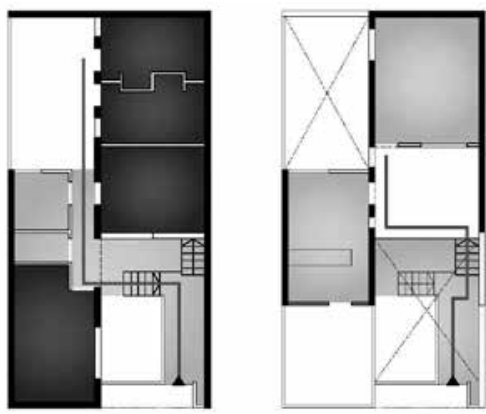

Integración:

Programa funcional

D: Dormitorio

S: Sala de estar

C: Comedor

K: Cocina

L: Lavadero

B: Baño
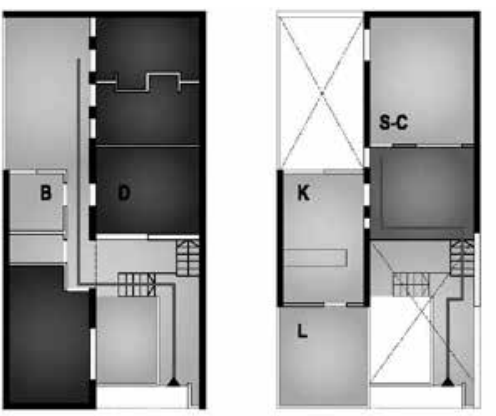


\section{Kikutake, Kurokawa y Maki (Japón)}

En este caso, el jurado valoró el sistema constructivo ligero. De la casa, su sección cruzada y la inserción de unidades producidas industrialmente para resolver los servicios (cocinas y baños) y el almacenaje. Parte del jurado encontró excesivos los espacios públicos centrales. Lo público se entiende aquí como apertura y ampliación de lo privado en un continuo que segrega el espacio con discreción. Dos paralelogramos, sencillo y doble, organizan el tráfico y sus diagonales enhebran el espacio público: jardines infantiles y plazas forman un itinerario a disposición del viandante o transeúnte.

Dos únicos tipos o módulos de habitáculo (superficies de 6 × 16 y 6 × 20 metros cuadrados) proveen a la mayor variedad con el menor número de elementos. De las estructuras se requiere que, además de su indispensable estabilidad (incluso a solicitaciones no comunes), provean acabados que hagan superflua cualquier especie de revestimiento, como no sea el sencillo maquillaje de una capa de color. Se estudian al detalle los equipamientos completos de las viviendas con baños y muebles modulados de prefabricación ligera, en cuyo diseño se pone el mayor esmero. La idea de alta densidad y baja altura es llevada al límite con un espíritu de saturación del espacio que alivia el sentido de un orden complejo (Figura 14).

La rica planimetría (de clara apariencia orgánica) del barrio contrasta con la uniformidad de los módulos puestos en juego y obliga a una diversidad de orientaciones, quizás más confiada a los beneficios de la convivencia que a los dones de la naturaleza. De hecho, esa planimetría produce una primera impresión de parking: como si las casas fueran caravanas estacionadas con la disciplina de un estilo de vida dictado
Figura 14.

Proyecto de Kikutake, Kurokawa y Maki (Japón)

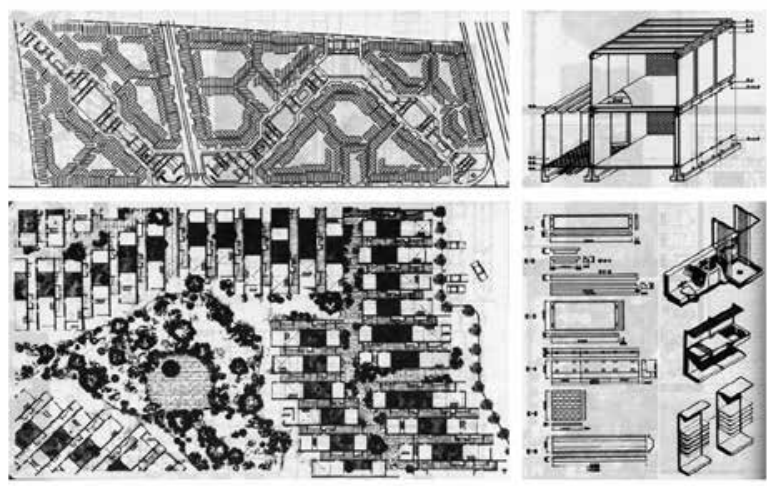

Fuente: Samper (s. f., p. 4)

por la docilidad. La serie ondulada de servicios surge como un tren de suministros provisional y estratégicamente detenido en este lugar, pero la realidad, corroborada por el crecimiento del modelo y abonada por el sentido común, excede a esa primera apariencia. La casa, concebida como un puente, al que son adyacentes los servicios, entre la calle y el pasaje, crece hacia arriba (alojamiento de la familia) y horizontal (comercio).

El patio es el pacto que discierne y distancia ambos programas: el de comercio y alquiler, que recae a la calle y el reservado a la familia, accesible desde el pasaje. Las escaleras proveen el crecimiento en altura y dividen las funciones. En este caso, el proyecto se concentra en la construcción de los espacios privados, en los que destaca la generosidad en cantidad y dimensión y confía al gran patio central tanto la vida en común de la familia, en una primera instancia, como el alojamiento de nuevas escaleras que permitan la independencia de accesos a los nuevos usos que se requieran, sin que por ello deje de funcionar como mecanismo de iluminación y ventilación de la vivienda (Figura 15). 
Figura 15.

Proyecto de Kikutake, Kurokawa, Maki (Japón). Dispositivos de crecimiento, funcionamiento e integración

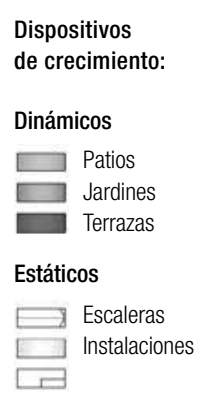

Funcionamiento

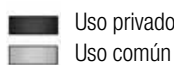

C Circulaciones

Integración:

Programa funcional

D: Dormitorio

S: Sala de estar

C: Comedor

K: Cocina

L: Lavadero

B: Baño
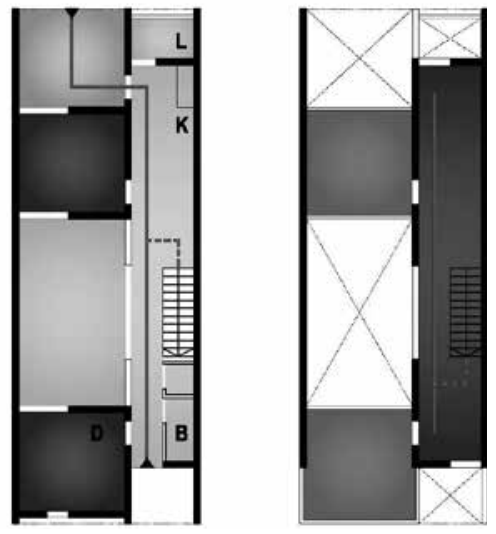

\section{Charles Correa (India)}

La alta densidad y la baja altura minimizan las vías. El espacio vital fagocita las vías de tránsito: se está mucho más que se viene y se va. Una vía principal, diagonal y quebrada, en donde la fluidez del tránsito se supedita a sus recodos-estaciones (escuelas, tiendas, iglesias, áreas de recreo), organiza el espacio público. Los vientos dominantes imponen sus reglas y la orientación, por eso, es uniforme, pero la ubicación, adyacente a las sendas, es sinuosa. A los árboles se confía la modulación del sol (porque sombrean), del viento (porque tamizan) y del ruido (porque mitigan). Las fachadas son angostas, en un gesto de modestia urbana. Las casas crecen y multiplican sus ámbitos, al dividirse en compartimentos, en primer lugar y luego, al añadir nuevos ámbitos a lo largo y a lo alto (pues lo ancho está limitado por la vecindad) (Figura 16).

\section{Figura 16.}

Proyecto de Charles Correa (India)
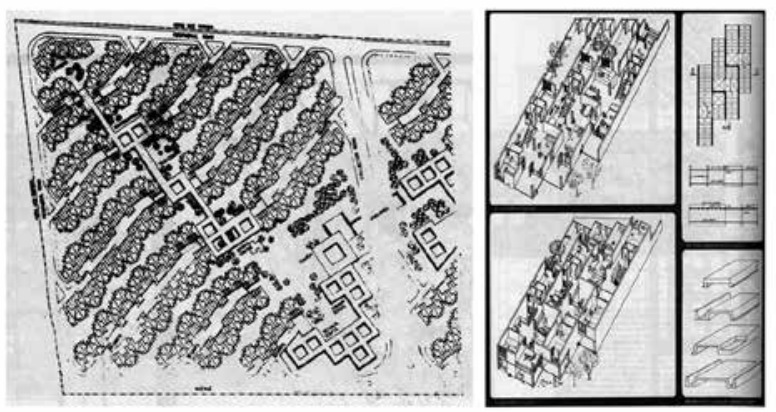

Fuente: Samper (s. f., p. 8)

Ahora bien: ¿¿debe ser tan drástica la separación entre viandantes y vehículos? Las discapacidades de algunos vecinos tal vez nos sugieran una consideración más matizada y menos radical de aquel principio dado por supuesto y definitivo. La planimetría de la propuesta suscita la metáfora arbórea: la planta urbanizada es como un árbol (una palmera) o como una hoja de árbol, más bien, con sus nervaduras principales y secundarias. En 
el tallo diagonal se alojan servicios públicos y en sus ramas se derrama el discurrir de paseantes. En su solidez, que deja un mínimo espacio libre, esta aglomeración, distendida en su astuta dislocación, evoca los antiguos poblados neolíticos (el de Chatal-Huyuk es un ejemplo) donde generosas azoteas compensan las calzadas ausentes.

El acierto más notable puede hallarse en la inteligente estructura dentada que, con el pulso de su sístole y diástole, rige el crecimiento al compás de la familia que primero aumenta y luego se desglosa (la casa, con el tiempo, deviene hostal), lo que no obsta para que un cierto desorden confunda la trama. En este caso, el proyecto opta por dotar, llenos de matices, los espacios para la vida en común de la familia y apunta, con el ejemplo, la dirección de los dormitorios que, sin duda, se añadirán (Figura 17).

\section{Knud Svenssons (Dinamarca)}

Partimos de un túnel: por él circulan los transeúntes y a él vierten comercios y otros servicios. La vida comunitaria se entierra como las raíces vegetales. Los caminos mandan, pero apenas se dejan ver; se comportan como infraestructuras (en sentido literal: no solo están debajo, sino por debajo). A ras de tierra florecen los habitáculos, aparentemente autónomos en su libre floración, como los hongos en el bosque. Homogéneos en su hechura, pero libres en su posición aleatoria, piezas de ajedrez en una partida a medio jugar. Cada unidad residencial cuenta con un área común y el barrio se despieza en vecindarios. $\mathrm{Pa}$ neles de hormigón pretensado consienten alturas hasta de tres plantas. En su distribución, solo baños y cocinas están prefijados, adyacentes a las correspondientes torres de instalaciones (como en la Plug-in-City). De todo ello se deriva un tapiz urbano que seduce por su aspecto disciplinado. En él se cumple la utopía de una prefabricación asequible que conjura la monotonía, sin detrimento del rigor económico (Figura 18).
Figura 17.

Proyecto de Charles Correa (India). Dispositivos de crecimiento, funcionamiento e integración
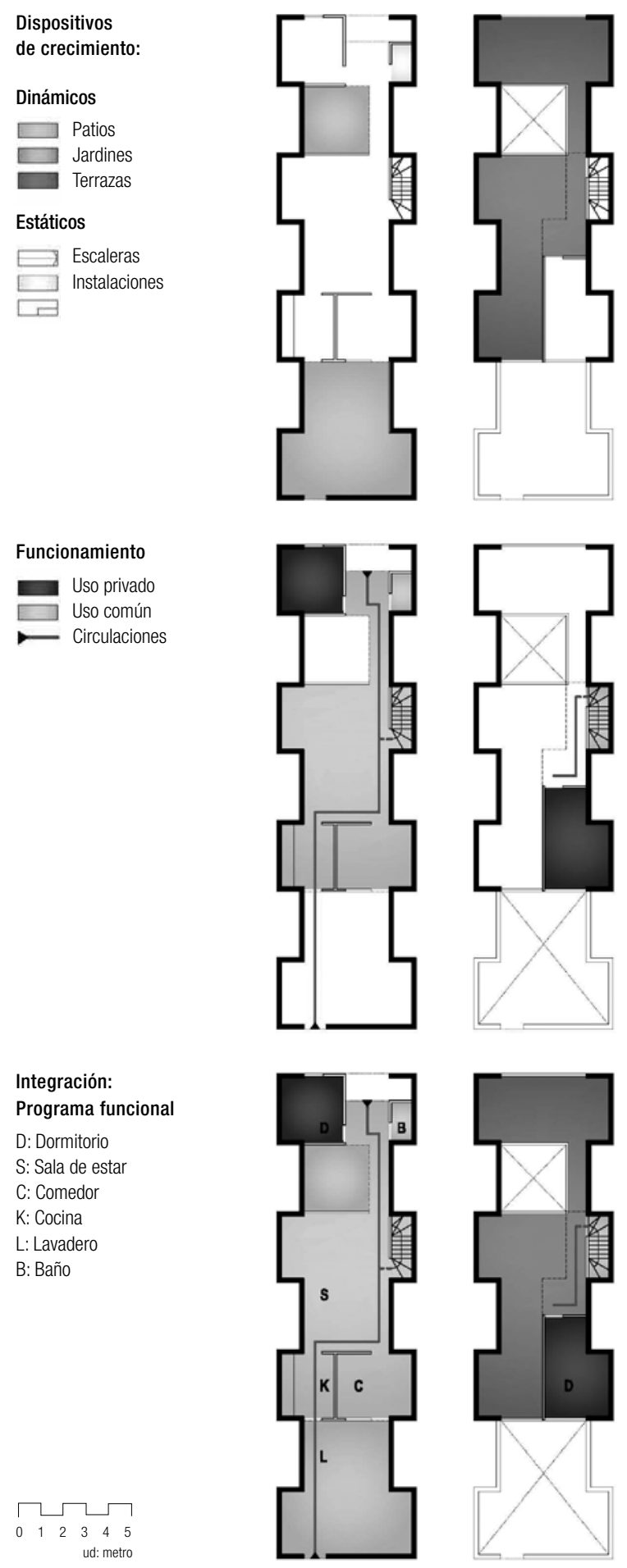

Fuente: elaboración propia 
Figura 18.

Proyecto de Knud Svenssons (Dinamarca)

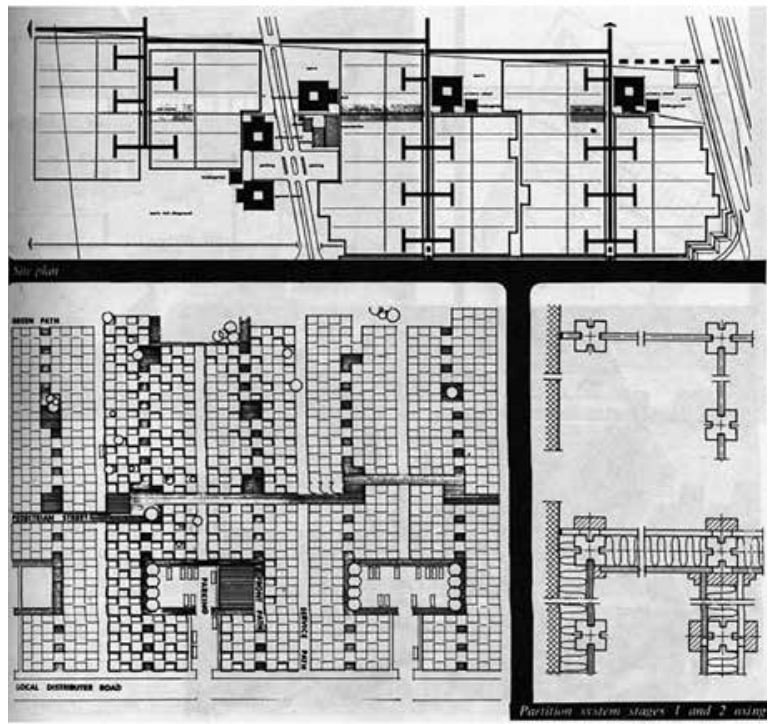

Fuente: Samper (s. f., p. 13)

Estar todo controlado, sin parecerlo, es una de las principales virtudes de esta propuesta que aplica esquemas de alta tecnología a soluciones de bajo coste e individuación suficiente. Su principal atractivo es tectónico: losas planas y casetonadas y muros nervados configuran los módulos-unidades. El crecimiento se presenta en el vuelo (hacia lo alto) y a costa de los patios, que lo absorben sin grave merma del espacio, generoso de origen, de sus luces y de su ventilación. Así, al saturar en parte el poroso damero, los habitáculos se multiplican sin desorden de la trama, que permanece fiel a sí misma. Escaleras y servicios invaden partes de ellos y algunos espacios se los apropian íntegros, a pesar de lo cual - y por lo esponjoso de la planificación - la habitabilidad queda a salvo. Resplandece el equilibrio entre los espacios privados y comunes de la vivienda en la que, una vez más, comprobamos que la disposición de los patios es clave para su expansión, flexibilidad y adaptación (Figura 19).
Figura 19.

Proyecto de Knud Svenssons (Dinamarca). Dispositivos de crecimiento, funcionamiento e integración
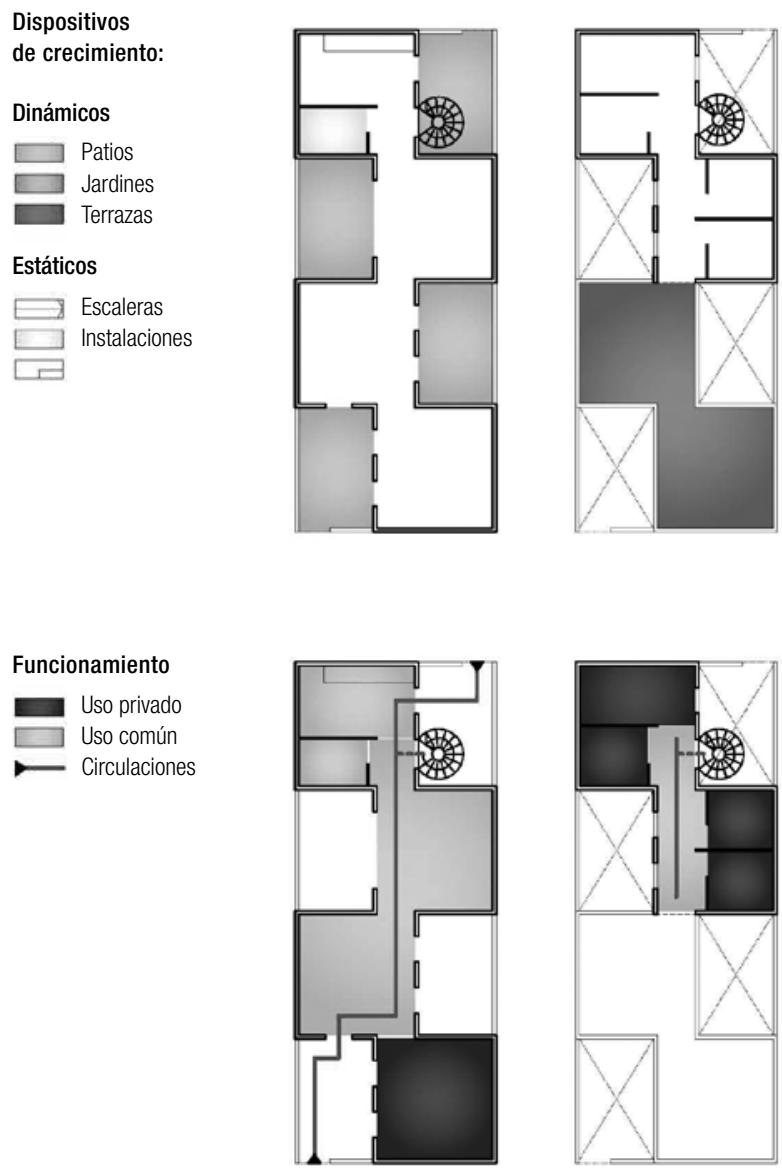

Integración: Programa funcional D: Dormitorio

S: Sala de estar

C: Comedor

K: Cocina

L: Lavadero

B: Baño
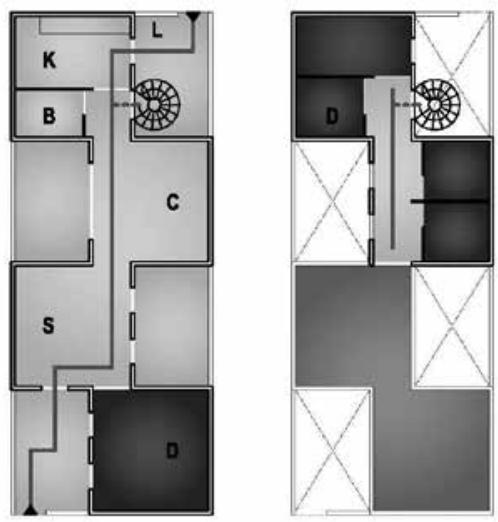

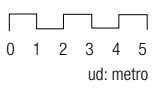

Fuente: elaboración propia 


\section{Conclusiones: balance}

Propósito fundacional y fundamental de este Concurso de arquitectura fue, como se ha dicho, llamar a escena al habitante, a su usuario y ocupante natural, para contar con su libertad (la que la vida reclama en un sentido pleno de la utilidad que trasciende el uso para alcanzar el disfrute) dentro de un orden (el que la edificación, para bien o para mal, impone): problema de no fácil solución.

El hecho arquitectónico es, de suyo, polifónico: en él hay diversidad de voces. $\mathrm{Al}$ arquitecto que lo proyecta y ejecuta (en la primera fase, al menos) le concierne concertarlas y convocar a una cierta armonía de todas ellas. Se trató, pues, no tanto de proveer soluciones, sino de sentar principios - "un problema bien planteado", se dice, "avanza en más de la mitad su solución”)—, habida cuenta de su necesario y previsible crecimiento. Las ciudades y los edificios crecen, hacia dentro y hacia afuera.

Para conjugar ambos crecimientos conviene, si no romper, al menos suavizar la dicotomía entre lo público y lo privado. Todo, en arquitectura, es privado y público a la vez, en cierta medida: la ciudad es doméstica (domus maxima) y la casa es urbana (civitas minima). Un proyecto de esta naturaleza supone la asunción de un equilibrio ponderado entre la tradición (a la que el usuario no puede ni quiere renunciar) y el progreso (del que el arquitecto no puede ni debe prescindir).

Dado que la premisa de partida es la renuncia al vuelo (altura), como condición económica, sobre las disposiciones del suelo recae la responsabilidad principal de la estructura urbana horizontal. Las vías rodadas y las sendas para viandantes son algo más que un gesto de planificación. Estas organizan el espacio privado/público y prolongan el de las viviendas, cuyo crecimiento regulan y definen sus lotes (sustitutos de las manzanas en la ciudad burguesa). En ellas se insertan las dotaciones colectivas.

Sus ejes vitales son distintos de los ejes viales del planeamiento convencional. Se descarta el $z o-$ ning, por supuesto; el tejido urbano es regular o irregular, según conviene, y se rige por otros parámetros (que lo irregular se lea como orgánico no deja de ser una metáfora banal). En cualquier caso, la economía impone el orden, que deberá conjugar los beneficios de la mecanización (la prefabricación ligera, por ejemplo, está presente y es oportuna) con el crecimiento aleatorio de las familias.

No por casualidad uno de los equipos favoritos (el japonés) que concurrió a esta convocatoria había lanzado hacia la misma época la referencia del metabolismo en los seres vivos (que transforma sustancias simples en otras complejas y viceversa) para ilustrar el encuentro de la arquitectura con la vida, utopía que retoma, más de cincuenta años después y a propósito del Previ, McGuirk (2011) en su artículo para Domus.

En efecto, si por una parte la arquitectura debe simplificar en sus disposiciones lo imprevisible de las funciones vitales y sociales, por otra, estas comprometen a la arquitectura con su dinámica compleja, real e imaginaria. Hallar un justo y ponderado equilibrio entre instancias contradictorias, como son modulación y movilidad, racionalidad y crecimiento, prefabricación e improvisación, oficios y espontaneidad, ha sido voluntad común de estos proyectos experimentales, con distinta fortuna, como es lógico.

Es curioso que, en el idioma español, "experimento" (acción y efecto de experimentar) sea masculino y "experiencia" (conocimiento de la vida adquirido por las circunstancias o situaciones vividas), femenino. Todo proyecto es un experimento que procede de la experiencia y 
conduce (o lo pretende) a ella. Un proyecto es (como la obra de arte, según Adorno) lo que llega a ser. ¿Acaso el viejo Neufert, manual de medidas para la edificación, inspirado en las normas DIN del Deutscher Werkbund, no se titula Arte de proyectar en arquitectura?

Es experimento que está a punto de hacerse o en trance de ser experiencia. En este Concurso, esa coyuntura, por otra parte natural y habitual, se asume de entrada. El proyecto de arquitectura no acaba en la obra ejecutada, porque la vida (que lo suscitó) sigue y es siempre obra inacabada. Una vida se acaba y otra y otra, pero la vida no, con lo cual la arquitectura permanece. Sus habitantes duermen, mas ella vela.

Es siempre, por vocación, provisional: viva. En la Arquitectura, como en el Arte, nada es definitivo, nada está acabado, acotado o cerrado, lo cual no es novedad, pero puede serlo. La toma de conciencia detiene el curso de los acontecimien-

\section{Bibliografía}

Bonilla di Tolla, E. (dir.) (2009). Lima y el Callao. Guia de arquitectura y paisaje. Lima:
Universidad Ricardo Palma, Junta de Andalucía, Aecid.

Crousse, J. (2008). La experiencia PREVI. En F. García-Huidobro, D. Torres Torriti y N. Tugas. ;El tiempo construye! (pp. 152-155). Barcelona: Gustavo Gili.

Fique, L. F. (2006). Concurso Internacional de Arquitectura y Urbanismo Elemental. Bitácora, 10(1), 207-215. Recuperado de dialnet.unirioja. es/descarga/articulo/4015041.pdf

García-Huidobro, F., Torres Torriti, D. y Tugas, N. (2005). Previ Lima: 35 años después. $A R Q$, (59), 72-76. Recuperado de http://www.redalyc. org/articulo.oa?id=37505916

García-Huidobro, F., Torres Torriti, D. y Tugas, N. (2008). ¡El tiempo construye! Barcelona: Gustavo Gili.

García-Huidobro, F., Torres Torriti, D. y Tugas, N. (2010). Previ Lima y la experiencia del tiempo. Revista Iberoamericana de Urbanismo, 1(3), 10-19. Recuperado de http://hdl.handle. net/2099/12264

Land, P. (2008). El Proyecto Experimental de Vivienda (PREVI) de Lima: antecedentes e ideas. En F. García-Huidobro, D. Torres Torriti y N. Tugas. jEl tiempo construye! (pp. 10-25). Barcelona: Gustavo Gili.

Lucas, P., Salas, J. y Barrionuevo, R. (2012). Cuarenta años del Previ-Lima: algunas enseñanzas para la industrialización de la vivienda de bajo coste en Latinoamérica. Informes de la Construcción, 64(525), 51-62. Recuperado de http://digital.csic.es/bitstream/10261/80014/1/ Informes $\% 20 \mathrm{de} \% 201 \mathrm{a} \% 20$ Construcci $\%$ C3\% B3n, \% 2064\%28525\% 29\%20\%20 51-62\%20\%282012\%29.pdf 
Martí, C. (2014). Las variaciones de la identidad. Ensayo sobre el tipo en arquitectura. En R. Devesa (editor de la serie), arquialtemas: 36. Barcelona: Fundación Arquia.

McGuirk, J. (2011). Previ: The Metabolist utopia. Domus. Recuperado de http://www. domusweb.it/en/architecture/2011/04/21/previ-the-metabolist-utopia.html

Montaner, J. M. (2008). Sistemas arquitectónicos contemporáneos. Barcelona: Gustavo Gili.

Pérez, A. L. y González, D. (2011). Previ Lima y Elemental Chile. Lecciones aprendidas. $A r-$ quitectura y Urbanismo, XXXII(3), 48-55.
Recuperado de http://rau.cujae.edu.cu/index. $\mathrm{php} / \mathrm{revistaau} /$ article/view/121/120

Previ-Lima. Low Cost Housing Project. (abril, 1970). Architectural Design, 40(4) (monográfico), 187-205. Recuperado de http://isites.harvard. edu/fs/docs/icb.topic892112.files/Previ/AD.pdf Samper, G. (s. f.). Una alternativa para América Latina. Escala, (52-53), 1-24.

Zabalbeascoa, A. (2011). Dos hacen la ciudad: el negocio inmobiliario y los pobres [Entrevista a Joan MacDonald, arquitecta]. El Pais semanal. Recuperado de http://elpais.com/diario/2011/05/15/eps/1305440813_850215.html 